\title{
The Journal of Protozoology
}

\begin{tabular}{lll} 
Volume 6 & February 1959 & Number 1 \\
\hline
\end{tabular}

J. ProtozooL. 6(1), 1-7 (1959).

\section{A Quarter Century Exploring Tetrahymena*}

\author{
ALFRED M. ELLIOTT \\ Department of Zoology, University of Michigan, Ann Arbor
}

SYNOPSIS. In reviewing 25 years of work on Tetrahymena, the author describes early difficulties experienced by himself and others in developing a chemically-defined medium and in defining the taxonomy of $T$. pyriformis. With identification of its essential requirements, a variety of nutritional studies revealed the close resemblance between the metabolic pathways of this ciliate and those of the chick and rat. This suggested studies on the effects of gamma radiation and the effect of antibiotics.

Attention then turned to the puzzle of the absence of conjugation in all strains of $T$. pyriformis then maintained in laboratories. The observation that these strains were all amicronucleate led to the discovery of mating types (with D. F. Gruchy). This brought up the problem of what constitutes a species and how it might be solved in $T$. pyriformis where clearly defined groups are set off from other similar groups (varieties) by a breeding barrier.

Another problem is whether a life cycle exists in this ciliate and if so, the role amicronucleate strains play in this cycle.

$I^{\mathrm{N}}$ SEEKING answers to problems in biology many investigators have found it rewarding to conduct an intensive study of a single organism, examining many facets of its life and getting whatever answers it will divulge, at least those answers that the investigator can comprehend. By coincidence I happen to belong to this group of organism-oriented biologists in that over a quarter century has been spent exploring a single species of ciliated protozoan. The longer I pursue the numerous problems for which this organism probably has the answers, the more it seems to expose my ignorance of most of its life processes. In this address I propose to trace the history of the contributions made by a few investigators who have employed the ciliate, Tetrahymena pyriformis, as their experimental tool.

In 1931 when R. P. Hall graciously agreed to champion me through the ordeals of a doctorate program at New York University, the matter of selecting an organism for study was solved when I came upon a rapidly-growing ciliate in a water sample taken from

* Address of the past president, Society of Protozoologists, delivered at Bloomington, Indiana, August 26, 1958.
The origin and obvious evolutionary success of these "genetically dead" strains are other problems that are considered.

The search for nutritional markers for genetic experiments inspired large-scale collections, including some from tropical habitats. Strains were found which differed in serine and pyridoxine requirements. Genetic analysis was hindered by the high lethality following conjugation, unsatisfactory mating behavior in some clones, and the complete absence of autogamy, the latter making it difficult to obtain homozygous clones. The use of $\mathrm{x}$-radiation yielded haploid individuals; when these were mated with diploid clones the resulting haploid progeny proved that the genes controlling mating type and pyridoxine synthesis resided in the micronucleus.

Genetic analysis of the serine and pyridoxine mutants supports the idea that $T$. pyriformis is more of an outbreeder than an inbreeder. Left for the future is an extension of our knowledge of the breeding system of $T$. pyriformis and ultimately to examine critically the factors responsible for the success of this ubiquitous ciliate.

Van Cortland Park in New York City. Without attempting to identify it, an effort was made to isolate clones in axenic media, following the tenets set down by André Lwoff who isolated his now classical Glaucoma piriformis 9 years before(30). Following 3 months of utter failure, one last effort produced a tube that contained the ciliate and was free of other microorganisms. In retrospect one can only be amused at the struggle that seemed necessary to obtain an axenic clone when today, with the advent of antibiotics. the technic is so simple. When I recall the maze of apparatus that was popular in those days in freeing cells of bacteria compared to the ease with which we have since established thousands of clones in axenic culture, I can only express a debt of gratitude to Flemming and others for developing modern antibiotics.

During this period, other workers, both in the United States and abroad, were busily engaged in isolating small ciliates in axenic media, all of which have since been identified as T. pyriformis (3). In 1927 Chatton in France isolated strain Ch-S(1). Glaser \& Coria isolated strain GC in 1930(22), and Hetherington isolated strain $\mathrm{H}$ in 1932(25). In 1933 both Thomas (strain $\mathrm{T}, 47$ ) and Elliott (strain E,7) re- 
ported the establishment of strains in axenic media. Other strains, in all over 20, were grown in axenic media during the ensuing years and together are now referred to as the "classical strains."

The problem of assigning a name to my strain plagued me from the time of its isolation, and continued to even after, in desperation, I called it Colpidium striatum based on a description by Stokes in 1886(45) and listed in Conn's "Protozoa of the fresh water of Connecticut" $(2)$. The taxonomy of these small ciliates was very confused; how confused became apparent in the late 1930's when W. H. Furgason tackled the problem. He visited my laboratory to have a look at my organism which was promptly identified as the same one he was calling Tetrahymena geleii. We owe him a debt of gratitude for his careful analysis of the buccal apparatus of this and closely related species and for giving us the appropriate name, Tetrahymena, for these ciliates $(21)$. We are also indebted to $\mathrm{J}$. O. Corliss for his vigorous attack on the problem of the taxonomy of this important Colpidium-Glaucoma-Leucophrys-Tetrahymena group from which has come a clarification of the relationships between them $(3,4)$.

The hope of finding a chemically-defined medium that would support growth of these ciliates probably was in the mind of most earlier investigators. Lwoff (31) had concluded, after attempting to grow his organism (now known as T. pyriformis, strain GL) on completely digested muscle, that it required a nitrogen source more complex than amino acids-indeed nothing more simple than peptides. In spite of these conclusions, I offered my ciliate media containing a variety of partially hydrolyzed incomplete proteins to which the missing amino acids had been added with the hope of discovering which ones were required. The futility of all these excursions became apparent some years later when the actual requirements were revealed. For example, methionine, now known to be required, was unavailable at this early period and another essential amino acid, threonine, was unknown. Certain essential growth factors were also yet to be discovered, hence any attempt to find a chemically-defined medium was doomed to failure before it was initiated.

By the end of 1936 it became quite clear to those working in this area that the hope of finding a chemically defined medium for $T$. pyriformis must wait until more was known about the nutrilites themselves. Fortunately, chemists were actively engaged in isolating more and more nutrilites essential for life of higher animals. Such workers as W. C. Rose(38) was making great strides in determining the amino acid requirements of mammals, employing his so-called single "omission" technic. As more pure amino acids and vitamins became available for study, work on the old problem of a chemically-defined medium for $T$. pyriformis was renewed.
In the early 1940's G. W. Kidder and his associates initiated their long and profitable series of investigetions on the nutrition of strain $W(29)$. They are responsible, more than anyone else, for working out the amino acid and vitamin requirements of $T$. pyriformis. They accurately determined the qualitative and quantitative requirement of one nutrilite after another until only one of the vitamins remained. The structural formula for this compound was finally determined in 1952 by E. L. R. Stokstad and his associates(46). Once 6-thioctic acid was available, $T$. pyriformis could be grown in a completely known medium and the goal that was sought 20 years earlier was finally realized. My only contribution was to search out the requirements for strain $\mathrm{E}$ which, with the exception of the serine requirement, are identical with strain $W(8.9)$.

This was a landmark in nutrition because no "animal" had been grown on a diet in which every molecule was known. I believe that this information has been helpful to workers in the several laboratories where single mammalian cells are currently being cultured in vitro $(6,39)$. There can be no doubt but that these successes will have great significance in our understanding of cellular growth and metabolism of normal and malignant cells.

The task of determining the essentiality of metals for any organism is extremely difficult and $T$. pyriformis is no exception. J. V. Slater became involved in this problem while studying the carbohydrate metabolism of strain $\mathrm{E}$ for his doctorate. By utilizing highly purified compounds and chelating agents he was able to demonstrate the essentiality of both cobalt and magnesium $(41,42)$. He further showed the quantitative uptake of radiocobalt and its rate of accumulation in the cell(43). His continued researches on other ions will certainly throw light on the function of these presently unknown constituents of the environment and protoplasm.

Once the nutrilites were known for $T$. pyriformis, metabolic studies could be undertaken with much more sophistication than was possible with any other animal cell. This ciliate became the cell of choice for such studies and the number of papers that began to appear in the literature rose rapidly and have continued up to the present $(5,40)$. These workers have made valuable contributions to the understanding of the metabolism of this cell which has been important in the understanding of cellular metabolism in general. Two examples from our laboratories will illustrate the kinds of investigations that have been undertaken. J. F. Hogg and I investigated a variety of compounds structurally and metabolically similar to the amino acids essential for strain $\mathrm{E}$ and found a remarkable correlation between those that would spare or replace the essential amino acids to those that would do the same for the chick and rat(26). This work merely indicates 
a similarity in basic metabolic pathways between $T$. pyriformis and higher animals, a fact that makes this cell a valuable tool in biochemical research where knowledge can be gained in days whereas many weeks are required with higher animals. Another case where this organism has been useful as a research tool was when J. A. Gross and I undertook a study of the effect of gamma radiation on nutrilites(10). The goal of this effort was to determine the damage, if any, these radiations had on food, a highly practical problem since a program of sterilizing food employing cobalt 60 was viewed as a new approach to food handling. Experiments with rats, chickens or mice were unsatisfactory for several reasons, the most significant being the cost of maintaining them on a chemically defined diet. When the ciliate was fed irradiated nutrilites many of them, particularly the vitamins, were damaged. T. pyriformis was able to answer the question quantitatively, which was almost impossible employing the usual laboratory animals.

In the early 1950's there was considerable interest centered around the effect antibiotics had on normal animal cells. J. A. Gross decided to study the mode of action of three of these compounds, chloramphenicol (Chloromycetin), chlortetracycline (Aureomycin), and oxytetracycline (Terramycin), for a doctoral problem, employing $T$. pyriformis as his normal animal cell. By studying inhibition of growth rate, reduction of maximal yield at the end of 4 days, and suppression of the time required to reach half-maximal growth, he was able to define rather critically the effect of these 3 antibiotics (23). This is another example of how $T$. pyriformis will answer questions that may not be answerable with the usual laboratory animal.

The biochemistry of this ciliate rapidly reached a level of sophistication that extended beyond my capabilities or interest so in $1951 \mathrm{I}$ turned my attention to an old problem that had plagued me for years, namely, why did T. pyriformis refuse to conjugate? Over a period of 19 years I had on numerous occasions mixed strains obtained from colleagues in the hopes of observing some sort of sexual activity (20). No combination stimulated the diverse clones to have the slightest interest in one another. A simple cytological test showed why: none had a micronucleus! It is highly unlikely that natural-occurring amicronucleate clones conjugate since we have never observed it among the large numbers that have been examined in the past 6 years. Since it seemed improbable that this species could maintain itself without a genetic mechanism for adapting to changing environmental conditions, a search was made for sexually active strains. In the fall of $1951 \mathrm{I}$ isolated 20 clones from water samples taken in the Ann Arbor area. It was my good fortune that D. L. Nanney had just arrived on our campus from Sonneborn's laboratory and that he indicated an interest in Tetrahymena. Another bit of good fortune was that in 10 of the 20 clones paired animals appeared which meant that they were undergoing that sexual aberration known as selfing (20). The regretable outcome of this embrace was death of both conjugants. This was not a new discovery since that remarkable Algerian librarian, Emile-Francois Maupas, had made a similar observation, probably on the same organism, many years before (32). Gratifying though this rediscovery was, it offered little that could be used for genetic studies. Obviously breeding clones that left viable offspring had to be found if $T$. pyriformis was to be used as a genetic tool.

Consequently, in the summer of 1952 D. F. Gruchy and I isolated 127 clones from 15 fresh-water habitats in the Woods Hole area. Notable among these habitats was Cary Pond, from which was obtained two clones, now designated WH6 and WH14, which conjugated, separated, survived, and would not mate within the clone(16). These have since been assigned to variety 1, mating types I and II. Another clone, WH52, from a different habitat, mated with both WH 6 and WH14 and was, therefore, assigned to mating type III. Subsequent tests demonstrated that they grew abundantly under axenic conditions and when subjected to the single-omission technic thrived on the same diet that supported strain E. Moreover, they lost none of their mating capacity under these artificial conditions. Careful cytological studies demonstrated no morphological differences between them (17). Since the three mating types were identical both in their nutrition and structure, it seemed at this point that genetic analysis must wait until diverse traits could be detected.

About this time D. F. Gruchy decided to search for other varieties and mating types as a doctoral problem. His efforts resulted in the discovery of seven more varieties (2-8) with varying numbers of mating types in each. He found two mating types each in varieties 5,7 , and 8 ; three each in varieties 4 and 6 ; eight in variety 3 ; and ten in variety $2(24)$. Since, Nanney \& Caughey (34) derived 4 more mating types in variety 1 , we found one more in variety 2 , making 11 , and five in a new variety, 9 , collected from the tropics. More recently one mating type has been added to variety $8(35)$ and a restudy of variety 2 indicates that it contains nine mating types instead of eleven(28). In all there exists over 40 mating types in the nine varieties (there may be many more) which constitute one of the largest breeding systems among the ciliates.

One is forced to give some thought to the problem of whether or not these nine varieties might be considered separate species since they are clearly isolated from one another by their failure to cross-breed. Other differences are becoming apparent as more careful 
studies are being made. Our recent seriological studies (unpublished) demonstrate marked varietal differences between them and in some cases even the mating types can be distinguished from one another in a single variety. Other physiological differences such as response to high temperatures, growth rates (unpublished), and utilization of nutrilites are known(27). Other differences include length of refractory and immaturity periods, both of which vary widely in those that have been studied. One must be cautious in interpreting these differences since many may be strain differences rather than differences characteristic of a variety or mating type. On the other hand, morphological similarities are striking, for example, representatives of all varieties that have been studied $(3,7$, and 8 are still to be studied cytologically) possess five pairs of chromosomes $(12,17,36,37)$. Moreover, even the morphology of the chromosomes themselves seems to be the same, that is, there is one large, one small, and three of intermediate size and all have median centromeres. Silverline preparations of representatives of the nine varieties reveal slight differences which Corliss (pers. comm.) considers only intraspecific variations. Confronted with these similarities and differences one must ask the old question-what limits of variation must exist before distinct breeding populations, within a so-called species, constitute new species?

Sonneborn(44) feels that to separate the 12 varieties of Paramecium aurelia into species would be a mistake and, therefore, suggests the name syngen for such reproductively isolated populations, leaving the word species to the taxonomists on the grounds of priority. He supports this thesis by a number of arguments, all of which have considerable merit. The difficulty of identification is cited as a major argument for keeping the present name variety or adopting the new one, syngen. This difficulty in identifying $P$. aurelia is equally true of $T$. pyriformis, even more so with our present state of ignorance of varietal characteristics. Sonneborn admits subtle morphological and physiological differences, in addition to mating behavior, between the varieties of $P$. aurelia. Similar differences in $T$. pyriformis are becoming apparent as more is learned about the different varieties. It seems to me that these minor differences together with the far greater and more significant breeding barrier that stands between the varieties provides us with sufficient information to erect valid species. I see no great state of confusion resulting if, for example, the nine varieties of $T$. pyriformis were identified as $T$. pyriformis 1 , for variety 1 , $T$. pyriformis 2 for variety 2, etc. This would be no more burdensome than our present system of variety numbers and to adopt such designations would be in keeping with our present system for the classification of all animals.
A life cycle may exist in $T$. pyriformis similar to that reported for Paramecium aurelia in which there exists a period of immaturity, followed by maturity and senility, ending in death of the clone(44). In searching for a similar life cycle in T. pyriformis one is always confronted with the classical strains, one of which has been in culture for over 35 years which suggests that such clones might go on indefinitely, hence do not possess a life cycle. It is important to note, however, that all of the classical strains are amicronucleate and are, therefore, genetically dead. Perhaps they should not be included as "normal" members of the species. Another significant fact is that as many as one-half of the collections taken in the United States and the tropics were amicronucleate which means that such clones do not occur sporadically but play a significant part in the maintainance of the species. Since they are genetically dead one would expect that they are destined for extinction because they possess no mechanism, aside from an occasional mutation, to adapt to their changing environment. Just how normal micronucleate clones give rise to amiconucleate clones in nature is not clear, although in the laboratory Nanney (33) finds in variety 1 that after 500 to 1500 fissions eccentric micronuclear division gives rise to non-viable amicronucleate cells. This observation does not explain the classical amicronucleate strains nor those that were isolated from nature within the past 5 years and are thriving in our laboratory at the present time. Two kinds of amicronucleates must arise, those that are destined for extinction and those that possess a sufficiently adequate genome to permit continued existence.

Sonneborn maintains that a life cycle exists in $T$. pyriformis similar to that in P. aurelia (44). Following conjugation a period of immaturity occurs which is followed by a long period of maturity during which conjugation takes place and viable offspring are produced. The first sign of senility is age-induced selfing which yields viable offspring at first but later gives rise to fewer and fewer survivors until all die. We have observed a small percentage of selfing clones in collections taken from nature but they leave no progeny since the process is lethal. Likewise selfers that arise from certain laboratory crosses leave no offspring. Our observations, therefore, confirm Sonneborn's contention that selfing is a sign of aging. Another sign of aging is the loss of the micronucleus in which event they may die soon or live a long time, as in the case of the classical strains. Obviously then it is safest for the organism to follow the latter course, sacrificing sex for immortality. That this is common practice is proven by the large percentage of amicronucleates in nature. It will be necessary to follow individual clones of $T$. pyriformis for long periods of time in the laboratory using representatives of all the varieties before 
one can be certain that a life cycle exists, although the available data seem to indicate that this ciliate may well possess one which differs in some respects from that found in P. aurelia.

In the fall of 1952, R. E. Hayes came to Michigan as a research associate and during the next two years we investigated the cytology and physiology of the original variety 1 mating types(17). About this time, C. Ray Jr. at Emory University became interested in $T$. pyriformis and subsequently brought his vast knowledge of cytogenetics to bear upon the cytology of this ciliate which has resulted in a thorough understanding of the events occurring during meiosis(37). His careful analysis of the chromosomes, their number, their morphology, their aberrations under a variety of conditions, has laid a firm foundation for future genetic studies.

Our search for biochemical differences in the hundreds of clones that were accumulating in our laboratory uncovered nothing. Exposing conjugating strains to varying dosages of $x$-irradiation, cobalt 60 , ultra violet light and chemical mutagens were likewise unsuccessful(18). Admittedly, finding such mutated cells is very difficult, yet it seemed the lesser of two bad choices to permit mother nature to induce them and then try to find them.

Consequently, I collected water samples from Mexico, Panama, and Colombia in 1954 with the thought that tropical waters might contain $T$. pyriformis with nutritional requirements different from those of the north temperate zone. These habitats ranged in elevation from sea level to 10,000 feet and temperatures from 8 to $35^{\circ} \mathrm{C}$. Of the 142 habitats examined, 30 contained $T$. pyriformis and from these 277 clones were isolated $(19)$. Preliminary testing of approximately 2500 clones taken from the United States, as well as those from the tropics, including some that had been derived from crosses, seemed to indicate that all were identical. They all required 11 amino acids and 7 B-vitamins. However, a more careful subsequent testing program revealed the presence of 6 clones that grew without serine, all in tropical variety $9(14)$, and 41 that grew without pyridoxine (15). With two biochemical tags it seemed a simple matter to analyze these traits. How wrong we were became evident two years later when only the most elementary analysis had been completed.

In the summer of 1955 , G. M. Clark, who had recently received his degree in cytogenetics from Emory University, came to Ann Arbor as a research associate. The inheritance pattern of these two mutants occupied our attention for the next two years. The term, mutant, as applied to these clones has a somewhat different meaning than that assigned to the usual biochemical mutant, which is one that requires one or more additional nutrilites than are required by the wild type.
In these cases the mutant requires one less nutrilite. Since the mutants synthetic powers are greater than those of the wild type, one might think of it as a "relict" species. At one time perhaps T. pyriformis could synthesize both serine and pyridoxine but because these nutrilites occurred in the environment in abundance there was no need for it to retain the enzyme systems necessary to continue these syntheses. It seems reasonable that the fewer nutrilites the organism was forced to manufacture the more its energy might be diverted into making those that were essential and thus could divide more rapidly than their ancestors and selection would favor their dominance in the population.

Since the loss of the ability to make serine and pyridoxine probably occurred recently, it seemed likely that the genes controlling these synthetic pathways might be most easily altered by mutagenic agents. Hence, we subjected both of the mutants to $\mathrm{x}$-radiations(13). The serine mutant remained unchanged, but out of the 27 pyridoxine non-requiring clones irradiated, 6 lost the ability to make the vitamin. These results indicate that the gene or genes controlling pyridoxine synthesis are susceptible to radiation damage and probably to other adverse environmental conditions, hence are more likely to be lost than those controlling other synthetic pathways.

Many difficulties were encountered in our genetic studies. Not all clones grow with equal vigor nor do they mate satisfactorily. It becomes necessary. therefore, to make many preliminary matings and select those that thrive in culture and mate best. In the serine work we had only one mating type among the 6 mutant clones, hence it was impossible to mate clones with this trait. This necessitated outbreeding with the wild type and selecting favorable clones from the progeny. Obviously there is a good deal of selecting among the available clones before the initial crosses can be made, and just how this influences the final results is conjectural.

Another difficulty, and one that was the most provoking of all, was the high lethality following conjugation. Some of the original crosses yielded as few as $1 \%$ viable offspring, which one might expect if the parents were becoming senile. One is hard pressed to explain how, in natural populations, a process so lethal as this can possibly be tolerated by a species. It seems hardly worth the chance of destroying $99 \%$ of the population in order to juggle the gene pool in the few survivors. Obviously it is not too detrimental since $T$. pyriformis survives in great abundance.

Before attempting to analyze the inheritance pattern of the genes controlling serine and pyridoxine synthesis we attempted to render our stocks homozygous. This could readily be done if $T$. pyriformis underwent autogamy which is common in $P$. aurelia and other cili- 
ates. In our examination of a great many slides of $T$. pyriformis we have never seen any kind of nuclear reorganization in single cells. Moreover, we have never been able to induce autogamy employing the methods that have been fruitful with other ciliates. Efforts were made to induce cytogamy by separating two conjugants during the early stages of meiosis and before the interchange of gametic nuclei. The use of detergents, proteolytic enzymes, electric and heat shock, all failed to separate the animals. Vigorous mechanical agitation, however, did accomplish the separation but the "exconjugants," instead of continuing in meiosis as was hoped, either remained in the stage they had reached when separated or became amicronucleate. None of the separated cells survived owing apparently to the irreparable damage inflicted when the cells were torn apart.

The remaining alternative, the induction of haploidy, seemed to be the approach most likely to succeed in our efforts to find some way of determining the genotype of a cell in one generation(11). We, therefore, irradiated strain UM 7 , variety 2 , mating type II, with varying dosages of $\mathrm{X}$-rays and isolated 20 clones from each level. These were then mated to clones which had received no radiation. Examination of these pairs during the entire process of conjugation showed no abnormalities until the level of radiation reached $400,000 \mathrm{r}$. One clone from this level failed to produce a viable migratory nucleus. Its normal mate, however, produced both stationary and migratory gametic nuclei, the latter passing over to the irradiated mate and there giving rise to the complete nuclear apparatus. The stationary nucleus did likewise, hence both mates were haploid. This was easily confirmed by chromosome counts when these haploids were crossed with normal cells.

In crosses between haploid and diploid cells the resulting progeny always possess the mating type of the diploid parent indicating that the genes controlling mating type were carried in the micronucleus. The haploid also told us that the gene or genes involved in pyridoxine synthesis were carried in the micronucleus. By crossing the haploid with the diploid pyridoxine mutant, the offspring both grew without pyridoxine, proving that the genes were carried from the diploid to the haploid in the gametic nucleus. It could also tell us whether the mutant was heterozygous or homozygous, since the ratio of the offspring would be $1: 1$ in the former and all of one category in the latter. While the haploid has considerable potential as a tool in determining the genotype of strains of $T$. pyriformis, the difficulties in obtaining haploids of the proper mating type as well as other technical obstacles, has made it less useful than was hoped.

As a result of thousands of crosses and more than 25.000 isolations over a 2 -year period, we finally have accumulated sufficient data to be able to make a few simple statements about the inheritance patterns of the genes controlling serine and pyridoxine synthesis. They are somewhat the same in both $(14,15)$.

Crosses between serine-requiring and non-requiring clones from natural habitats give rise to progeny that are numerically equally distributed between the two categories. Most of the progeny from crosses between two serine non-requiring clones require serine, with a few segregating out that do not need the amino acid. These data indicate that the gene or genes controlling the serine non-requirement are recessive to the wild type which requires serine. Growth of the $F_{1}$ progeny was highly variable. Some clones failed to survive on serine-deficient media and were, therefore, tentatively assigned the homozygous dominate genotype. The remaining clones were of two classes: one grew slowly on serine-deficient media and was said to be heterozygous; the other grew without serine, hence were double recessives. The $F_{2}$ progeny resulting from crosses of the double recessives need no serine whereas the cross of the heterozygote with the recessive homozygote resulted in equal numbers of serine-requiring and non-requiring clones. The cross of two heterozygotes yields progeny approximating the $3: 1$ ratio in favor of the serine non-requiring clones. Crosses at the $F_{3}$ level produced inviable offspring in all cases except one. Recessive homozygous progeny from this cross were mated and the resulting offspring grew without serine. The ratios were always skewed $t$ )ward the heterozygote indicating that this genotype possesses a more satisfactory genome for survival.

When two clones that do not require exogenous pyridoxine were crossed, all progeny grew without the vitamin. Offspring from crosses of two wild-type pyridoxine-requiring clones need the vitamin with the exception of a few that get along without it. The ratio is approximately $3: 1$ favoring the requiring category. Matings involving the homozygous dominant pyridoxine-requiring with the double recessive nonrequiring clones yield progeny that need the vitamin. Test-crossing these heterozygotes with the parental double recessive non-requiring clones yield progeny in approximately 3 non-requirers to 1 requirer. All data indicate selection against either homozygote. In both the serine and pyridoxine studies the great abundance of heterozygotes and rarity of homozygotes in natural habitats corroborates these findings. In both, the genetic evidence supports a single-gene hypothesis although the possibility of multiple closely linked genes cannot be ignored. There is also the possibility that dominant suppressor genes may function in blocking the activity of the serine and pyridoxine mutant genes. Furthermore, the data definitely support an outbreeding economy. This is further supported by the mating type studies. The presence of an immaturity period 
and multiple mating types in most varieties fosters outbreeding and I think that $T$. pyriformis is probably more of an outbreder than an inbreeder although until more data are obtained on all of the varieties no definite statement can be made.

We have only begun to unravel the multitude of problems this tiny ciliate poses. As investigators discover its secrets. all biology will profit because the mysteries locked up in $T$. pyriformis are the mysteries of life itself.

\section{REFERENCES}

1. Chatton. E. \& Chatton, M. 1927. Sur les conditions nécessaires pour déterminer expérimentalement la conjugaison de l'infusoire Glaucoma scintillans. Compt. rend. 185, 400-2.

2. Conn, H. W. 1905. The protozoa of the fresh water of Connecticut. State Geol. Nat. History Survey Bull. 2, 49.

3. Corliss, J. O. 1952. Comparative studies on holotrichous ciliates in the Colpidium-Glaucoma-Leucophrys-Tetrahymena group. I. General considerations and history of strains in pure culture. Trans. Am. Microscop. Soc. 71, 159-84.

4. - 1953. Comparative studies on holotrichous ciliates in the Colpidiun-Glaucoma-Leucophrys-Tetrathymena group. II. Morphology, life cycles and systematic status of strains in pure culture. Parasitology 43, 49-87.

5. - 1954. The literature on Tetrahymena: Its history, growth, and recent trends. J. Protozool. 1, 156-69.

6. Eagle, H. 1955. The specific amino acid requirements of a mammalian cell (strain L) in tissue culture. J. Biol. Chem. 214, 961-4.

7. Elliott, A. M. 1933. Isolation of Colpidium striatum Stokes in bacteria-free cultures and the relation of growth to $\mathrm{pH}$ of the medium. Biol. Bull. 65, 45-56.

8. - 1949. The amino acid requirements of Tetrahymena geleii (E). Physiol. Zoöl. 22, 337-45.

9. 1950. The growth-factor requirements of Tetrahymena geleii (E). Physiol. Zoöl. 23, 85-91.

10. Elliott, A. M., Brownell, L. E. \& Gross, J. A. 1954. The use of Tetrah ynena to evaluate the effects of gamma radiation on essential nutrilites. J. Protozool. 1, 193-9.

11. Elliott, A. M. \& Clark, G. M. 1956. The induction of haploidy in Tetrahymena pyriformis following $\mathrm{x}$-irradiation. J. Protozool. 3, 181-8.

12. - 19.37. The mating type system in variety nine of Tetrahymena pyriformis. Biol. Bull. 113, 344.

13. - 1957. X-radiation effects during conjugation of Tetrahymena pyriformis. Biol. Bull. 113, 345 .

14. - 1958. Genetic studies of the serine mutant in variety nine of Tetrahymena pyriformis. J. Protozool. 5, 240-6. 15. - 1958. Genetic studies of the pyridoxine mutant in variety two of Tetrahymena pyriformis. J. Protozool. 5, $235-40$.

16. Elliott, A. M. \& Gruchy, D. F. 1952. The occurrence of mating types in Tetrahymena. Biol. Bull. 103, 301.

17. Elliott, A. M. \& Hayes, R. E. 1953. Mating types in Tetrahymena. Biol. Bull. 105, 269-84.

18. - 1954. Search for biochemical mutations in Tetrahymena. J. Protozool. $1,2$.

19. 1955. Tetrahymena from Mexico, Panama, and Colombia, with special reference to sexuality. $J$. Protozool. 2, 75-80.

20. Elliott, A. M. \& Nanney, D. L. 1952. Conjugation in Tetrahymena. Science 116, 33-4.
21. Furgason, W. H. 1940. The significant cytostomal pattern of the Glaucoma-Colpidium group, and a proposed new genus and species, Tetrahymena geleii. Arch. Protistenk. 94, $224-66$.

22. Glaser, R. W. \& Coria, N. A. 1930. Methods for the pure culture of certain protozoa. J. Exp. Med. 51, 787-806,

23. Gross, J. A. 1955. A comparison of different criteria for determining the effects of antibiotics on Tetrahymena pyriformis E. J. Protozool. 2, 42-7.

24. Gruchy, D. F. 1955. The breeding system and distribution of Tetrahymena pyriformis. J. Protozool. 2, 178-85.

25. Hetherington, A. 1932. The constant culture of Stentor coerulleus. Arch. Protistenk. 76, 118-29.

26. Hogg, J. F. \& Elliott, A. M. 1951. Comparative amino acid metabolism of Tetrahymena geleii. J. Biol. Chem. 192, $131-9$

27. Holz, G, G., Ir. \& Erwin, J. 1938. Physiological differences among mating types and varieties of Tetrahymena pyriformis. Anat. Rec. 131, 567.

28. Hurst, D. D 1958. The breeding system of variety 2 of Tetrahymena pyriformis. Dissertation, Univ. Michigan.

29. Kidder, G. W. \& Dewey, V. C. 1951. The biochemistry of ciliates in pure culture. Biochemistry and Physiology of Protozoa (Lwoff, A., ed.) Vol. I, 323-400.

30. Lwoff, A. 1932. Sur la nutrition des infusoires. Compt. rend., 176, 928-30.

31. - 1932. Recherches biochemiques sur la nutrition des protozoaires. Le Pouvoir de synthèse. Monogr. Inst. Pasteur, Paris

32. Maupas, E. 1889. La rejeunissement karyogamique chez les ciliés. Arch. Zool. Exp. Gén. 7, 149-517.

33. Nanney, D. L. 1957. Inbreeding degeneration in Tetrahymena. Genetics $42,137-46$.

34. Nanney, D. L. \& Caughey, P. A. 1953. Mating type determination in Tetrahymena pyriformis. Proc. Natl. Acad. Sci. U. S. 39, 1057-63.

35. Orias, E. 1958. The breeding system of variety 8 , Tetrahymena pyriformis. J. Protozool. 5,17

36. Ray, C. Jr. 1955. Meiosis and nuclear behavior in Tetrahvmena pyriformis. J. Protozool. 3, 88-96.

37. Ray, C., Jr. \& Elliott, A. M. 1954. Chromosome number of four varieties of Tetrahymena. Anat. Rec. 120, 228.

38. Rose, W. C. 1938. The nutritive significance of the amino acids. Physiol. Rev. 18, 109-36.

39. Sato, G., Fisher, H. W. \& Puck, T. T. 1957. Molecular growth requirements of single mammalian cells. Science 126, $961-4$.

40. Seaman, G. R. 1955. Metabolism of free-living ciliates. Biochemistry and Physiology of Protosoa (Hutner. S. H. \& Lwoff, A., eds.), 2, 91-158.

41. Slater, J. V. 1952. The influence of cobalt on the growth of the protozoan, Tetrahymena. Physiol. Zoöl. 25, 323-32.

42. - - 1952. The magnesium requirement of Tetrahymena. Physiol. Zoöl. 25, 283-7.

43. - 1957. Radiocobalt accumulation in Tetrahymena. Biol. Bull. 112, 390-9.

44. Sonneborn, T. M. 1957. Breeding systems, reproductive methods, and species problems in protozoa. In The Species Problem, Am. Assoc. Adv. Sci., Washington, D.C., 155-324.

45. Stokes, A. C. 1886. Some new infusoria from American waters. Ann. Mag. Nat. Hist. 5, 98-112.

46. Stokstad, E. L. R., Hoffman, C. E., Regan, M. A., Fordham, D. \& Jukes, T. H. 1949. An unknown growth factor essential for Tetrahymena geleit. Arch. Biochem. 20, 75-82.

47. Taylor, C. V., Thomas, J. O. \& Brown, M. G. 1933. Studies on protozoa. IV. Lethal effects of the x-radiation of a sterile culture medium for Colpidium camplum. Physiol. Zoöl. 6, 467-92. 